\title{
Algo sobre a Europa Thomas More
}

\author{
Rui Pina Coelho
}
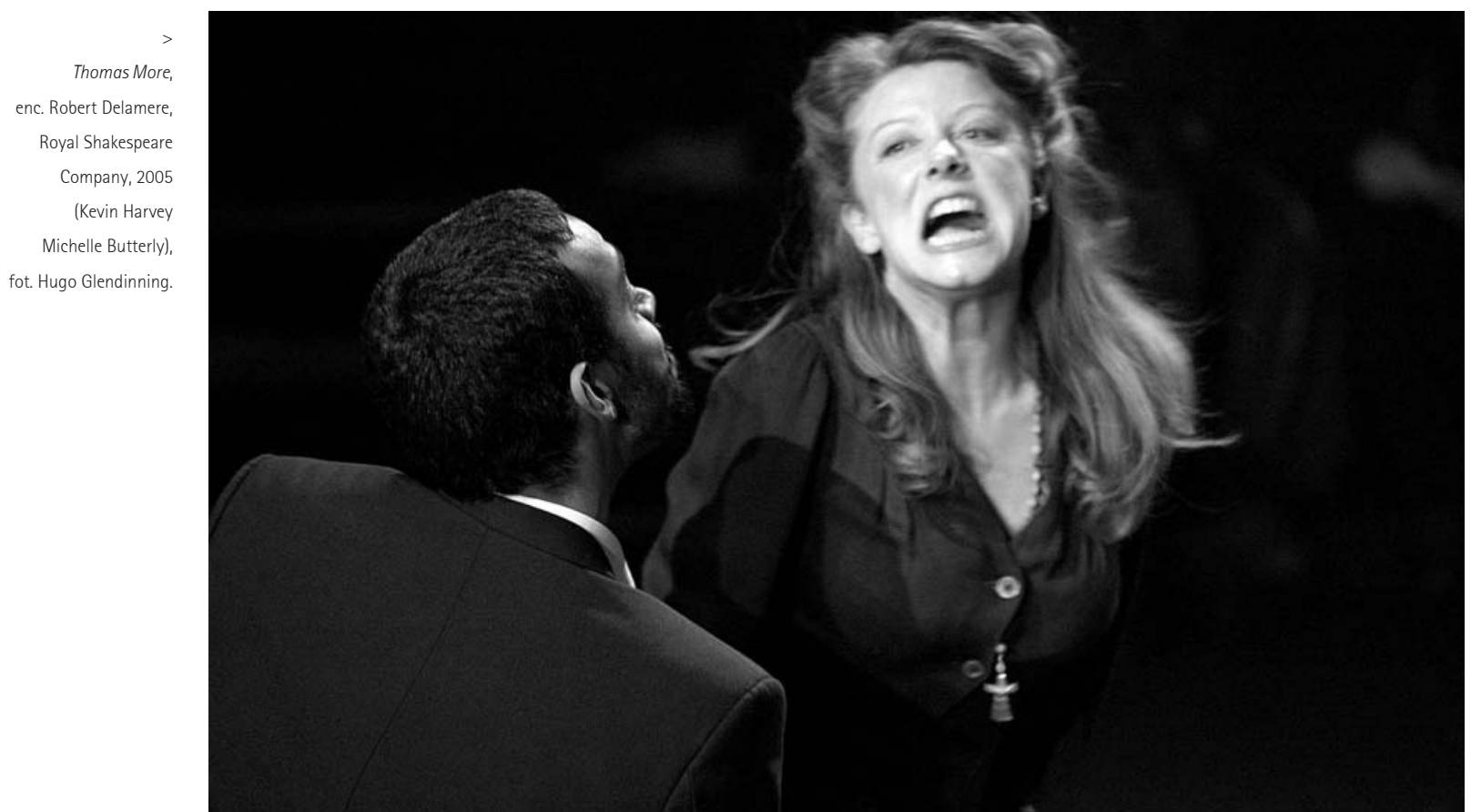

Em palcos portugueses, o autor de Utopia (1516)

foi figura central do

espectáculo Tomás More pelo Teatro Estúdio de Lisboa, com encenacão tradução de Luzia Maria

Martins, em 1965,

a partir do texto

A Man for All Seasons (1960), de Robert Bolt

(1924-1995).

Para além de Thomas More, esta temporada temática da RSC integra A New Way to Please You or The Old Law. de Thomas Middleton e

William Rowley

Believe What You Will,

de Philip Massinger,

Sejanus - His Fall, de Ben Jonson,

Titulo: Thomas More (c. 1592-94). Autor: Anthony Munday, Henry Chettle, Thomas Dekker, Thomas Heywood e William Shakespeare. Encenação: Robert Delamere. Cenografia: Simon Higlett. Desenho de luz: Wayne Dowdeswell. Música: Ilona Sekacz. Som: Mike Compton. Figurinos: Christopher Porter. Produção: Royal Shakespeare Company. Local e data de estreia: Swan Theatre, Stratford-upon-Avon, 9 de Março de 2005

Já perto do final do espectáculo, Sir Thomas More' (Nigel Cooke) sobe dois degraus que o levarão à morte. 0 primeiro degrau é um caixote onde já antes tinha reunido as armas dos manifestantes revoltosos. 0 segundo é a cadeira onde estava sentado quando recusa obedecer a Henrique VIII. São representações dos dois momentos chave do espectáculo que termina, tal como a vida do homem que Ihe dá o título, numa execução por traição.

Thomas More abre a Gunpowder Season ${ }^{2}$ da Royal Shakespeare Company (RSC), que assinala os 400 anos da Conspiração da Pólvora (Gunpowder Plot) de 1605. Sendo tido como certo que a autoria do texto é de Anthony Munday (c.1553-1633) e Henry Chettle (c.1560-1607), a versão final é o resultado da revisão e reescrita de cinco autores, que se crêem ser, para além dos já referidos, Thomas Dekker (c.1572-c.1632), Thomas Heywood (c.15741641) e William Shakespeare (1564-1616). Será escusado dizer que é a participação deste último que aporta inusitado interesse a esta obra. Apesar de tão valorosas contribuições, não há registos de que tenha sido representada na época isabelina ou jacobita, o que também se explica pela censura a que o texto foi sujeito. A encenação de Robert Delamere trata-se, portanto, da primeira grande produção desta obra.

A figura central da peça é, obviamente, Sir Thomas

More (1478-1535), mas este texto traz-nos algo mais que uma biografia. Logo no início do espectáculo, um estrangeiro ataca uma mulher inglesa. Então, como resposta, alguns londrinos organizam violentos ataques a todos aqueles que não sejam realmente ingleses. A populaça só se acalma perante as eloquentes palavras de More, que Ihes promete perdão real em troca da deposição das armas. Contudo, 0 perdão não chega a tempo e o líder da revolta, John Lincoln, é executado. Termina aqui a primeira parte do espectáculo, onde acompanhamos também a ascensão de More na hierarquia política inglesa. A segunda parte é marcada pela recusa de More em assinar "uns artigos" - que na peça nunca são explicitados -, desafiando assim a autoridade de Henrique VIII, e pelas consequentes represálias impostas pelo monarca que culminam na sua execução.

0 texto, embora partindo de factos históricos, tomaos de maneira bastante livre. Assim, as primeiras sete cenas resolvem rapidamente os doze anos que Thomas More 
demora a chegar a Lord Chancellor e a morte de Lincoln sintetiza a execução de 13 revoltosos, de entre os 278 prisioneiros resultantes dos motins anti-imigrantes de Maio de 1517.

0 Thomas More que aqui é apresentado é o amigo do povo, o justo defensor dos pobres, aquele que não tem medo de afrontar a autoridade (o punho fechado na cena final é evocativo disso mesmo) - é, enfim, um herói londrino. Nigel Cooke corporiza na justa medida esta figura, emprestando-Ihe um corpo frágil e magro, servido por um olhar penetrante. A composição de um More arguto e eloquente é delineada logo na primeira cena em que aparece, onde defende em julgamento um carteirista, salvando-o de uma condenação certa. Este aspecto vai, ao longo do espectáculo, sendo reforçado em vários momentos: pelo respeito manifestado pelos guardas que o vigiam na Torre de Londres; pelo carinho com que os seus criados o lembram; na visita que uma mulher anónima the faz no cárcere, despedindo-se dizendo: "Adeus ao melhor amigo que os pobres jamais tiveram"; e, sobretudo, pelo papel que desempenha no apaziguamento dos revoltosos.

A atmosfera social é criada com algumas cenas avulsas - o que também é indício da multiplicidade de penas envolvidas na escrita do texto -, tais como a cena do carteirista, a de Faulkner, o rufião ou a cena da execução de Lincoln. São personagens pícaras que convocam um ambiente sombrio e obscuro, onde não falta um toque de crítica e humor. Delamere serve-nos esta tenebrosa Londres seiscentista com luzes cruas e frias, cenários despojados, com muitas sombras e londrinos vestidos de fato e gravata, onde o preto, o branco e os cinzentos são as cores dominantes. Os actores representam próximos do público, utilizando, sobretudo para entradas e saídas, as potencialidades cénicas do Swan Theatre, provocando aparições verdadeiramente inesperadas. 0 ritmo do espectáculo é rápido, eléctrico, sendo que em cena estão quase sempre três ou mais actores. Ao fundo,

frequentemente na penumbra, estão os que esperam a sua cena para entrar. Sente-se uma presença brechtiana em tudo isto: no tom político, no anacronismo que os figurinos criam, na crueza das luzes (sobretudo na cena do motim e no final), na simplicidade e no pragmatismo dos cenários (compostos por várias combinações entre duas mesas, algumas cadeiras e caixotes), nas cenas de multidão (que a juventude do elenco torna verdadeiramente electrizantes), na interpretação de música ao vivo onde um violino e um acordeão agudizam algumas passagens, e na bancada onde os actores assistem como espectadores à acção que no palco se desenrola.
A tonalidade escura do espectáculo é invadida por vezes pelo vermelho da bandeira inglesa que ora aparece em destaque, ora surge esquecida em algum canto do cenário: vermelho este que lembra recorrentemente que é a pátria que legitima quer as agressões aos estrangeiros quer a recusa de More em assinar o que Henrique VIII Ihe pede; mas um vermelho que é também uma promessa certa de sangue...

Um dos momentos mais preciosos do espectáculo é a cena de "teatro dentro do teatro" (III.3). Momentos antes de ser chamado à presença de Henrique VIII e de Ihe desafiar a autoridade, More recebe em sua casa uma companhia itinerante de actores que vem apresentar a (nada inocente) peça The Marriage of Wit and Wisdom. Dado o atraso de um actor, o próprio More tem que representar um papel: o de Wit. A cena é uma evocação do ambiente de cabaré alemão dos anos 20 - não faltando sequer um engraçado sotaque alemão ao actor que interpreta em travesti Lady Vanity, num claro pastiche de Marlene Dietrich. 0 que acontece aqui é também a confirmação de More como aquele que corporiza o casamento entre um espírito arguto e a sabedoria. Ele é aquele que defende os mais fracos, 0 anfitrião bem disposto e o alegre conviva, mas é também o homem de Estado e o erudito respeitado.

Quando se cria uma personagem com todos estes atributos, o facto de a irmos mais tarde encontrar na prisão e assistirmos à sua execução, é muito mais terrivel. Sublinhase com isto o desacerto de um mundo que permite que homens como o Thomas More que aqui é desenhado venham a morrer às mãos da irracionalidade do Estado. Delamere é muito preciso nesta metáfora, apresentandonos esta personagem, na cena da prisão, literalmente de pernas para o ar: assim, um mundo às avessas é aquele em que Sir Thomas More é morto.

Não obstante tudo isto, o dado mais pertinente e perturbador deste espectáculo, é precisamente o que constitui a primeira parte: a revolta anti-imigrante, justamente o motivo pelo qual o texto foi censurado e proibido no século XVI, por promover a instabilidade social.

Os revoltosos agem motivados pela falta de segurança e, sabe-se, também pela falta de emprego. Para a Europa de 2005 esta é uma questão sobremaneira actual. A crescente migração populacional em busca de melhores condições de vida e de trabalho tem levado a que a questão da xenofobia esteja na ordem do dia. Contudo, os revoltosos são aqui gente simples, trabalhadora, que responde a uma primeira agressão - vejam-se as armas que More reúne após estas serem depostas: vários instrumentos de trabalho, tais como uma faca de talhante, um bastão, um serrote, 
Thomas More, enc. Robert Delamere,

Royal Shakespeare

Company, 2005

(Nigel Cooke),

fot. Hugo Glendinning.

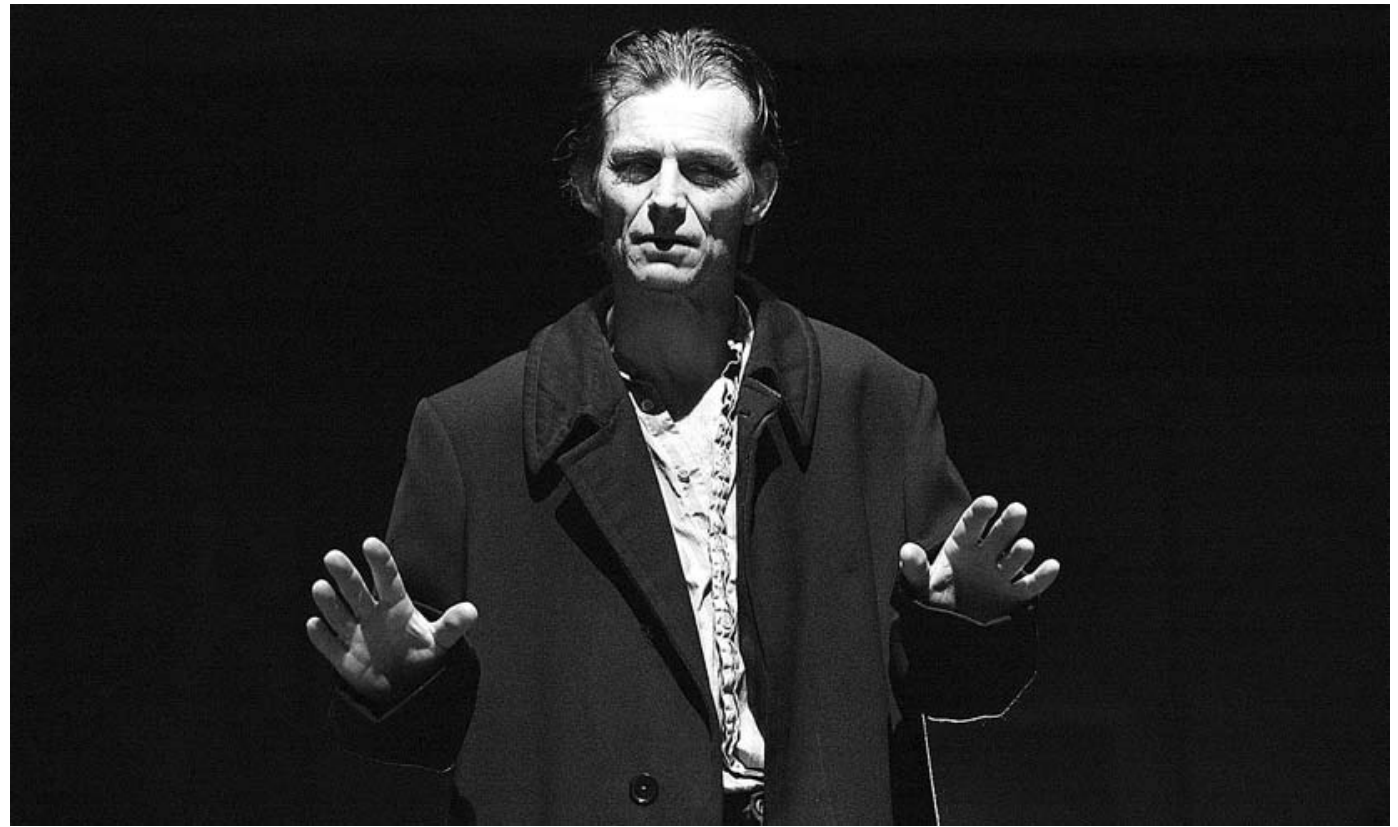

Thomas More,

enc. Robert Delamere,

Royal Shakespeare

Company, 2005

(Jon Foster, Peter Bramhill,

Michelle Butterly),

fot. Hugo Glendinning.

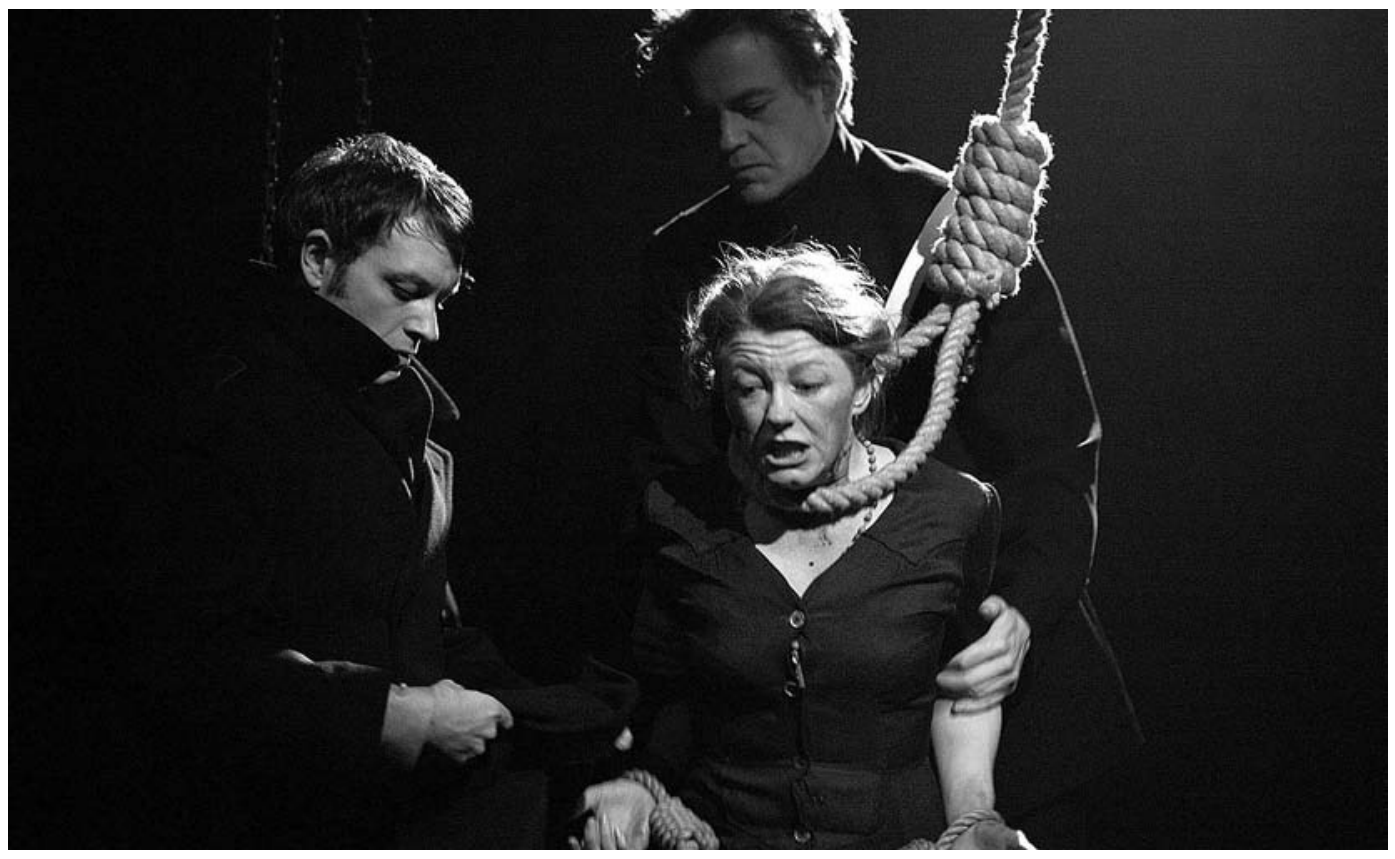

${ }^{3}$ Esta situação levou mesmo à implementação, a partir de 2004, por parte do executivo liderado por Tony Blair, da campanha Alcohol Harm Reduction Strategy for England. Para

além dos alcoólicos crónicos, esta campanha visa lidar com os binge-

drinkers, aqueles que bebem para ficarem rapidamente intoxicados, normalmente com menos de 25 anos, vendo-se

frequentemente associados a acidentes e situações de violência. um pé-de-cabra... (Há também uma garrafa de cerveja, clara alusão aos problemas que o Reino Unido tem com o alcoolismo, frequentemente associado à violência e ao racismo ${ }^{3}$ ). A atitude xenófoba e racista desta revolta é travestida de justiça, o que se torna bastante inquietante para o espectador contemporâneo. 0 discurso de More aos amotinados (II.4) - aquele que é tido como sendo da autoria de William Shakespeare - também não ajuda a sossegar: os argumentos utilizados por More vão no sentido de proteger os insurrectos das represálias do rei, pois, caso fossem expulsos do país, também eles se encontrariam em situação de alteridade. Toda a argumentação é bastante ambígua, sendo o 'politicamente correcto' aqui bastante sinuoso.

Mas, a este espectáculo acontece algo que poucas vezes acontece a uma obra de arte. Durante a sua carreira (Março-Novembro 2005), aconteceu o Julho de 2005 e os atentados terroristas em Londres. Como ler este espectáculo depois disto? Como 'ler' a revolta anti-imigrante depois de Julho de 2005?

Censurada na altura por mostrar londrinos muito pouco tolerantes para com os estrangeiros, este texto ganha no Verão de 2005 uma leitura muito mais inquietante. Se a encenação de Delamere construía o seu sentido dramatúrgico na confrontação do olhar moderno politicamente correcto com aquilo que poderá ser historicamente condenável esse hábil jogo ganha novo e assustador significado quando os revoltosos podem passar a ser os campeões da cidade, dado que expressam um sentimento comum à maioria dos actuais londrinos. 0 questionamento sobre a justeza ou não da revolta é elidido. John Lincoln deixa de ser um homem toldado por um racismo primário para ser um mártir... E se isto não estaria na mira de Delamere, a história recente encarregou-se de Ihe dar esta terrivel leitura. $\mathrm{E}$ nesta medida, este espectáculo ensina-nos algo sobre a nossa, cada vez mais complicada, Europa. 